\title{
Treatment and prevention of cardiac arrhythmias with propranolol and quinidine
}

\author{
Sh omo Stern \\ From the Cardiovascular Service, Hadassah University Hospital \\ and Hebrew University-Hadassah Medical School, ferusalem, Israel
}

Treatment or prevention of various cardiac arrhythmias was attempted by the combined use of propranolol and quinidine in small doses, in 221 patient trials.

Favourable results were achieved in converting chronic atrial fibrillation to sinus rhythm, in terminating paroxysms of atrial fibrillation and flutter, and in long-term prevention of atrial fibrillation and supraventricular and ventricular premature beats. Side effects were relatively few.

The successful use of propranolol and quinidine in combination may be attributed to a common and additive antiarrhythmic activity of the two drugs, while their other cardiac properties differ. $A$ hitherto unclarified 'interaction' between the two drugs may explain that by their joint administration untoward effects may become less than the sum of the effects induced by each drug alone.

Favourable results in converting patients with chronic atrial fibrillation to sinus rhythm with the combined use of small doses of propranolol and quinidine were described in earlier reports (Stern, 1967; Stern and Borman, 1969). The paucity of complications in these patients drew attention to the possibility that the adverse effects of larger doses of these drugs, i.e. the myocardial depressant or hypotensive action, may be lessened by their combined administration in a lower dosage, while their therapeutic effect may even be enhanced. Therefore, we have tried this combined drug regimen for treatment and prevention of various disturbances of cardiac rhythm in more than 200 patients, and the results are described below.

\section{Results}

Elective conversion of chronic atrial fibrillation This was attempted in 51 patients (Table).

The procedure was similar to that described in our previous report (Stern, 1967), and it can be briefly summarized as follows. Propranolol ro mg 3 to 4 times a day alone was administered for 3 days, and subsequently $0.2 \mathrm{~g}$ quinidine 3 to 4 times a day was added to the propranolol for a further 3 to 4 days.

Received 7 October 1970.
Thirty-six of the patients completed the above regimen in sinus rhythm.

In all 15 unsuccessful trials, subsequent electrical conversion was performed; this resulted in sinus rhythm in 5 patients. On the other hand, out of the 36 successful drug conversions, in 6 patients previous trials of electrical conversion had been unsuccessful.

Early postoperative conversion of chronic atrial fibrillation This was performed in 13 patients who had chronic atrial fibrillation before operation. Five to 21 days after open-heart surgery (mainly for mitral valve replacement), an attempt was made using the above detailed regimen to restore sinus rhythm. This was successful in 9 patients.

Paroxysmal atrial fibrillation During such an attack 16 patients received oral propranolol in a total dose of $20-50 \mathrm{mg}$, coupled with total dose of oral quinidine $0 \cdot 4-\mathrm{r} \cdot 0 \mathrm{~g}$. The paroxysm was terminated in 14 patients within to to 70 minutes.

Paroxysmal atrial flutter Four attacks in 3 patients could be terminated by oral administration of a total dose of $30-80 \mathrm{mg}$ propranolol, together with $0 \cdot 6-\mathrm{r} \cdot 6 \mathrm{~g}$ quinidine, within 10-60 minutes. 
Prevention of recurrence of atrial flbrillation In 72 patients with chronic atrial fibrillation in whom sinus rhythm was achieved either by drug treatment (43 patients) or by electrical cardioversion (29 patients) propranolol and quinidine were used in combination as the maintenance treatment. The dose of propranolol was 5-10 $\mathrm{mg}$ three to four times daily together with $0.2 \mathrm{~g}$ quinidine three to four times daily. Sinus rhythm could be maintained for at least one year in 74 per cent, and for at least two years in 33 per cent of the patients.

Treatment of supraventricular premature beats Thirty-four patients were treated for this condition with propranolol in an average daily dose of $15-30 \mathrm{mg}$, combined with an average daily dose of $0.6-0.8 \mathrm{~g}$ quinidine. Disappearance of the arrhythmia was observed in 19 patients, and reduction in frequency in 8 patients. This effect was maintained by using this drug regimen during a follow-up period of at least 12 months. In 6 of the patients, the treatment was successful only after an increase in dosage of the drugs.

Treatment of ventricular premature beats This condition was successfully treated in 19 out of 28 patients with the above-mentioned schedule. Continuation of the treatment as maintenance therapy successfully prevented recurrence of the premature beats in 16 of these patients for at least 12 months.

Prevention of ventricular tachycardia In 4 patients with recurrent ventricular tachycardia, prevention of attacks was tried using a daily dose of $30-40 \mathrm{mg}$ propranolol and $0.8-$ $1 \cdot 2 \mathrm{~g}$ quinidine. In 2 of them further attacks have been prevented by this regimen now for more than 18 months.

Side effects encountered In one patient, lescribed in detail in an earlier communicaion (Stern and Borman, 1969), hypotension ind bradycardia occurred after pretreatment with propranolol, when quinidine was added; ntravenous isoprenaline restored blood presire and heart rate to normal levels. In anther patient less severe hypotension occurred luring the pretreatment period, with a total lose of $30 \mathrm{mg}$ propranolol, for an attempted :lective drug conversion of atrial fibrillation. Jiscontinuation of the drug was followed by pontaneous restoration of blood pressure. Jne patient with chronic rheumatic mitral alve disease developed pulmonary oedema vhile receiying the combined treatment. She
TABLE Patients with attempted conversion of chronic atrial fibrillation to sinus rhythm

\begin{tabular}{llll}
\hline Aetiology & $\begin{array}{l}\text { No. of } \\
\text { patients }\end{array}$ & $\begin{array}{l}\text { Mean } \\
\text { duration } \\
\text { of atrial } \\
\text { fibrillation } \\
(y r)\end{array}$ & $\begin{array}{l}\text { Sinus } \\
\text { rhythm } \\
\text { achieved }\end{array}$ \\
\hline Rheumatic heart disease (no cardiac surgery) & I6 & 2.6 & 10 \\
Rheumatic heart disease (at least 3 months & 21 & $2 \cdot 3$ & 17 \\
after cardiac surgery) & I3 & $3 \cdot 2$ & 8 \\
Arteriosclerotic heart disease & I & $<3$ & 1 \\
Idiopathic & & & \\
\hline
\end{tabular}

was in another hospital where the attack cleared up with conventional treatment. A clear-cut connexion between pulmonary oedema and the quinidine and propranolol treatment was not established, but further administration of the drugs was discontinued.

The administration of propranolol was followed by praecordial discomfort in 2 patients, 'difficulties in breathing' in I, and severe sinus bradycardia without blood pressure change in another patient. Discontinuing propranolol resulted in disappearance of these side effects.

Contraindications for treatment The usual contraindications for each of the drugs individually, such as quinidine sensitivity, bundle-branch block, atrioventricular block, bronchial asthma, congestive heart failure, etc., were taken into account when considering their combined use.

\section{Discussion}

Propranolol and quinidine have many pharmacological properties in common, such as the local anaesthetic action, skeletal neuromuscular depression, etc. Both drugs have been shown to reduce the height and rate of rise of the action potential in isolated myocardium (Williams, 1966). Moreover, both drugs were shown to inhibit calcium uptake by the sarcoplasmic reticulum of the myocardium (Shinebourne, White, and Hamer, 1969). All the similar properties suggest an additive, enhancing action of the two drugs. However, the situation appears to be more complex, if one takes into consideration recent observations showing that some cardiac actions of the two drugs differ significantly.

By recording His bundle electrograms, Berkowitz et al. (1969) showed that propranolol, unlike quinidine, does not prolong intraventricular conduction; therefore, the hazard of provoking a re-entry arrhythmia with this agent is minimal, and, in contrast to quinidine, 
propranolol seems not to induce ventricular arrhythmias. Propranolol was found to shorten the QT ${ }_{c}$ interval of the electrocardiogram of normal subjects (Stern and Eisenberg, I969); this effect is remarkably different from the well-known prolongation of the $\mathrm{QT}_{\mathrm{c}}$ interval after quinidine. Visioli et al. (1969) showed shortening of the electrical systole time in normal subjects after administration of another beta-blocking agent, Butiridine I, in contrast to the prolonging effect of quinidine. Sano et al. (1968) found that small doses of propranolol, sufficient to terminate atrial fibrillation, did not influence the rate of rise of action potential. The distribution and local concentration of the two drugs within the myocardial cell is different; propranolol is concentrated in the vicinity of the $Z$ lines and settles with the microsomal fraction (Masuoka, Alcaraz, and Earle, 1967), suggesting binding to sarcoplasmic reticulum, while quinidine is predominantly bound to the cell membrane, and its concentration in sarcoplasmic reticulum is less (Conn, 1964). Moreover, the incorporation of tritiated leucine into myocardial proteins is inhibited by quinidine, but not by propranolol (Beller and Mongillo, 1969).

The fact that beta-blocking agents and quinidine share the basic antiarrhythmic activity, but differ in many other important cardiac actions, may be the clue to the encouraging clinical results achieved by their combined use. Though the variety of basic clinical conditions, differences in indications for treatment, etc., make comparisons between the results of different antiarrhythmic therapies extremely difficult, our results seem to compare favourably with the results of other investigators (Radford and Evans, 1968; Byrne-Quinn and Wing, 1970). Reports of the successful combined administration of propranolol and quinidine have been noted also by other groups of investigators (Reynolds and VanderArk, 1967; Visioli and Bertaccini, 1968). Dimich et al. (1970) described a child in whom the combination of propranolol and procainamide was effective on paroxysms of ventricular tachycardia and their prevention, though individual administration of these drugs was ineffective. Vettori et al. (1968) combined quinidine with another betablocking agent (trasicor) and reported good success. In contrast, Hillestad and Storstein (1969), in an attempt to convert 21 patients with combined propranolol and quinidine treatment, succeeded in only 5 instances and, because of side effects, found this treatment dangerous. However, it should be mentioned that the two fatalities reported in their communication cannot be attributed with abso- lute certainty to the combined treatment, since one death occurred from cerebral embolus 24 hours after cessation of treatment, whereas the other, a patient who had extensive myocardial fibrosis, occurred while on propranolol only.

A 'negative interaction' between quinidine and beta-blocking drugs was recently studied, experimentally, by Bertaccini et al. (1968) and Stern (197I) and, clinically, by Visioli and coworkers (1969). These investigators showed that by the joint administration of these drugs, the negative inotropic effect of the combination became less than the sum of the effects induced by each drug alone. Berger and Mokler (1969) noted that the prolongation of the effective refractory period induced by quinidine was decreased when beta-blocking or stimulating agents were administered together with quinidine, and the existence of competition for the available beta-receptor sites between the blockers or the stimulators and quinidine was proposed by the authors. On the other hand, the antiarrhythmic activity of propranolol and quinidine is additive, as proved in the recent investigation of Berger (1969). The bradycardia induced by propranolol may be another clue for the successful combination of the two drugs, since Johnson and McKinnon (1957) demonstrated, and Kennedy and West (1969) confirmed, that the negative inotropic effect of quinidine at fast heart rates becomes a positive inotropism at a slower heart rate.

\section{References}

Beller, B. M., and Mongillo, S. (1969). Inhibition of incorporation of leucine into myocardial proteins of the rat by antiarrhythmic agents. Circulation Research, 25, 401.

Berger, J. E. (1969). Interaction of adrenergic blocking agents with quinidine on chloroform induced arrhythmias. Pharmacologist, II, 245.

Berger, J. E., and Mokler, C. M. (1969). The interaction of quinidine with alpha and beta adrenergic receptors in the rat myocardium. fournal of Pharmacology and Experimental Therapeutics, 165, 242.

Berkowitz, W. D., Wit, A. L., Steiner, C., Lau, S. H., and Damato, A. N. (1969). The effects of propranolol on atrioventricular and intraventricular conduction. American fournal of Cardiology, 23, ro6.

Bertaccini, M., Impicciatore, M., Visioli, O., and Malagnino, G. (1968). Effects of interaction of antiarrhythmic drugs and beta-blocking agents on the isolated rabbit heart. Archives Internationales de Pharmacodynamie et de Thérapie, 176, 209.

Byrne-Quinn, E., and Wing, A. J. (1970). Maintenance of sinus rhythm after DC reversion of atrial fibrillation. A double-blind controlled trial of longacting quinidine bisulphate. British Heart fournal, 32, 370.

Conn, H. L., Jr. (1964). Quinidine as an antiarrhythmic agent. In Advances in Cardiopulmonary Diseases, p. 286. Ed. by A. L. Banyai and B. L. Gordon. Year Book Medical Publishers, Chicago. 
Dimich, I., Steinfeld, L., Richman, R., and Lasser, R. (1970). Treatment of recurrent paroxysmal ventricular tachycardia. American Heart fournal, 79, 811 .

Hillestad, L., and Storstein, O. (1969). Conversion of chronic atrial fibrillation to sinus rhythm with combined propranolol and quinidine treatment. American Heart fournal, 77, 137.

Johnson, E. A., and McKinnon, M. G. (1957). The differential effect of quinidine and pyrilamine on the myocardial action potential at various rates of stimulation. Fournal of Pharmacology and Experimental Therapeutics, 120, 460.

Kennedy, B. L., and West, T. C. (1969). Factors influencing quinidine-induced changes in excitability and contractility. Fournal of Pharmacology and Experimental Therapeutics, 168, 47.

Masuoka, D., Alcaraz, A., and Earle, R. (1967). The subcellular binding of propranolol in rat heart. fournal of Pharmacy and Pharmacology, 19, 479.

Radford, M. D., and Evans, D. W. (1968). Long-term results of DC reversion of atrial fibrillation. British Heart fournal, 30, $9 \mathrm{I}$.

Reynolds, E. W., and VanderArk, C. R. (1967). Treatment of quinidine-resistant arrhythmias with the combined use of quinidine and propranolol (Abstract). Circulation, 36, Suppl. 2, 22 I.

Sano, T., Suzuki, F., Sato, S., and Iida, Y. (1968). Mode of action of new antiarrhythmic agents. fapanese Heart fournal, 9, $16 \mathrm{r}$.

Shinebourne, E., White, R., and Hamer, J. (1969). A qualitative distinction between the beta-receptorblocking and local anesthetic actions of antiarrhythmic agents. Circulation Research, 24, 835.
Stern, S. (1967). Conversion of chronic atrial fibrillation to sinus rhythm with combined propranolol and quinidine treatment. American Heart fournal, 74, 170.

Stern, S. (197I). Hemodynamic changes following separate and combined administration of betablocking drugs and quinidine. European fournal of Clinical Investigation. In the press.

Stern, S., and Borman, J. B. (1969). Early conversion of atrial fibrillation after open-heart surgery by combined propranolol and quinidine treatment. Israel fournal of Medical Sciences, 5, 102.

Stern, S., and Eisenberg, S. (1969). The effect of propranolol (Inderal) on the electrocardiogram of normal subjects. American Heart fournal, 77, 192.

Vettori, G., Erle, G., Magaraggia, L., and Bau, G. (1968). Conversion of atrial fibrillation into sinusal rhythm by means of association of quinidine and a new beta adrenergic blocking agent (Abstract). In $V$ European Congress of Cardiology, p. 369.

Visioli, O., and Bertaccini, G. (1968). Combined propranolol and quinidine treatment in cardiac arrhythmias. American Heart fournal, 75, 719.

Visioli, O., Botti, G., Tagliavini, S., Poti, R., and Bertaccini, G. (1969). Effects of interaction of quinidine and beta-blocking agents on some cardiodynamic and hemodynamic parameters of normal individuals. American Heart fournal, 78, 217.

Williams, E. M. Vaughan (1966). Mode of action of beta receptor antagonists on cardiac muscle. American fournal of Cardiology, 18, 399. 